\title{
Poster
}

\section{EFFECT OF AEROBIC AND ANAEROBIC EXERCISE ON BASAL METABOLIC-RATE}

Moradhvaj Singh, D K Dureha, Santosh Yaduvanshi, Pooja Mishra Department of Physical Education, Banaras Hindu University, Varanasi, Uttar Pradesh, India

10.1136/bjsm.2010.078725.87

Lack of activity destroys the good condition of every human being, while moment and methodical physical exercise save it and preserve it. Psychic tensions, anxieties, obesity, BP, etc, in sedentary people have now swelled (grew larger) to enormous proportions. Exercise or physical activities help in handling all this by increasing basal metabolic rate (BMR). The research findings could remove several misconceptions about exercise and remove the mystical sheath over it. Many people do not perform any exercise and are unaware of this fact. Proper exercise profoundly improves our BMR. The exercise is intimately connected with our State of Health and improper BMR will often reflect various disturbances of body and mind. The purpose of the study was to investigate the effect of aerobic and anaerobic exercise on BMR. For this study, 40 male and 20 female students from BPE group were randomly selected as subjects from LNUPE, Gwalior. The subjects were divided into two groups, that is, one experimental group and one control group. Experimental group was administered with aerobic and anaerobic exercise and second group was control group that did not participate in training programme. The quantitative measurement of each subject was taken with the help of standard equipment, before and after the treatment period of $2 \mathrm{~h}$. The selected physiological variables were resting BMR administered in the Laboratory of Health Science and Yoga, LNUPE, Gwalior. The random group design applied for the effect of exercise on $B M R$. The analysis of resting BMR changes on the practice was positive of aerobic and anaerobic exercise subjects. 